\title{
EFFECTS OF PAVEMENT SURFACE DEFORMATIONS ON TRAFFIC FLOW
}

\author{
Metin Mutlu AYDIN ${ }^{1^{*}}$, Ali TOPAL ${ }^{2}$ \\ ${ }^{1}$ Dept of Civil Engineering, Faculty of Engineering and Natural Sciences, Gümüşhane University, Gümüşhane, Turkey \\ ${ }^{2}$ Dept of Civil Engineering, Faculty of Engineering, Dokuz Eylül University, İzmir, Turkey
}

Received 3 September 2016; revised 2 January 2017, 21 February 2017; accepted 16 March 2017

\begin{abstract}
Pavement surface deformations have a significant effect on speed profile of vehicles and traffic flow conditions. These deformations limit driving properties and increase vehicle operation and maintenance costs. Additionally, they cause many problems such as accidents, slower movement speeds, capacity loss and severe discomfort states. There are many factors having an effect on road capacities and they vary according to different road and traffic flow conditions. In this study, it is aimed to investigate and develop models to estimate shockwave and bottleneck forming, capacity loss and speed reduction, which occurred on examined road links caused by pavement deformations. For the prediction of road capacity, flow-density $(q-k)$ relationship, bottleneck and shockwave analysis methods were used. In the scope this study, deformed road links were divided into three sections; Section A - before deformation zone, Section B - deformation zone, and Section $\mathrm{C}$ - after deformation zone. All three sections were investigated and empirical results were obtained. According to analysis results, it was found that pavement surface deformations have a negative effect on the level of road service capability. Obtained results also showed that there are significant reductions in capacity relatively by up to 44 and $26 \%$ would result from surface deformations on deformed lanes and non-deformed adjacent lanes.
\end{abstract}

Keywords: capacity loss, shockwave, bottleneck, pavement surface deformation, traffic flow.

\section{Introduction}

Pavements are designed according to a predicted traffic carrying capacity for a designed service life (Ben-Edigbe, Ferguson 2005). After some time upon opening a road to traffic, various deformations and cracks begin to occur on the road surface such as raveling, polishing, rutting, swelling and shoving, potholes, transverse, longitudinal and alligator cracks etc. (Brown 1995; Aydın, Topal 2016; TRRL 1991). Road surface deformations are defined as any change on a road surface compared with the initial state of construction along the service life (Aydın et al. 2013; TRRL 1991). Deformations generally occur from the environmental (weather conditions and material properties) and structural (repeated traffic loads) effects (Walker et al. 2002). Surface deformations have the same effect such a "fixed" bottleneck similar to car accidents and roads with slopes and their effect can be investigated by using suggested traffic flow and car following models with a blockage (Kurata, Nagatani 2003; Chen et al. 2013, 2014). They may negatively affect serviceability of a road in relation to position and size on deformed pavement surface and work zone (Aydın 2012; Ghasemlou et al. 2016). They also have a significant impact on vehicle speed, traffic flow conditions and traffic accidents (Akgüngör, Doğan 2009; Prentkovskis et al. 2010, 2012; Dell'Acqua, Russo 2011; Aydın, Topal 2016; Dell'Acqua et al. 2016). Deformations limit driving properties such as vehicle control, driving comfort and also cause an increasing on traffic accidents, vehicle operating and maintenance costs. Additionally, they not only cause for traffic congestion problems and crashes, they but also cause slower movement speeds, longer journey times, longer queuing, higher traffic based noise and severe discomfort problems (Akgüngör, Demirel 2008; Ben-Edigbe 2010, 2016; Dell'Acqua, Russo 2011; Aydın, Topal 2016). To determine and prevent deformation problems, many countries have been worked to monitor road surfaces steadily by using special devices and techniques (TRB 2004; TRRL 1991; Lee, Kim 2005; TRB 2010; Dell'Acqua et al. 2011; Strazdins et al. 2011; Žilioniené et al. 2013; Aydın, Topal 2016). However, in order to investigate the negative effects of those deformations, several studies were conducted. In their study, Aydin et al. (2014) attempted to determine negative effects of deformations on drivers

${ }^{*}$ Corresponding author. E-mail: metinmutluaydin@gmail.com 
with modelling the lane choice behaviour of the drivers by using artificial neural networks and linear regression analysis. They concluded that lane changing for a vehicle was negatively related to the approach speed. Hence, if a vehicle has higher approach speed, the less likely it is that the driver would change his/her lane due to a surface deformation. In another study, Jiang, Li (2002) analysed positions, speeds and delays of vehicles and capacities of roads on work zones by using Global Positioning Systems (GPS) devices. They found that GPS data ensures sensitivity about time, location and speed of the vehicles to define the real queue length and delay time before the work zone. Jiang (1999) investigated traffic delays resulted from the decelerations of the vehicles, which are approaching to the Deformation Zone (DZ). According to obtained results, Jiang (1990) reported that road surface deformations have a negative effect on vehicle speeds and traffic delays. In a similar study, Aydın, Topal (2016) examined the effect of pavement deformations on lateral lane utilization and longitudinal driving behaviours. From the study results, they found that if a DZ has wider area and less depth, it will be less effective on lateral lane utilization of vehicles. Study results also show that variation in other parameters such as deformation type, depth and height are associated with the lateral lane utilization of drivers. Additionally, it was also found from the analysis that the drivers' characteristics such as perception and aggressiveness are the most important factors, which influence longitudinal vehicle behaviours while passing through the DZs.

Although many procedures and standards have been proposed to conventionally measure to discomfort inflicted by road surface deformations on a driver in a moving vehicle. In reality, studies about the effect on traffic capacities are very limited and they may not be related to the fact that weak pavement properties. Some earlier results show that deformations have a great effect on uninterrupted road link capacity (Ben-Edigbe, Ferguson 2005). There are many effective factors on road capacities and they vary according to different road and traffic flow conditions. In their study, Ben-Edigbe, Mashros (2012) investigated the extent of highway capacity drop caused by road humps, and they found that there was significance drop in capacity of roads. However, the results of conducted some studies show that potholes on pavement surfaces may reduce speeds average $6 \mathrm{~km} / \mathrm{h}$ (Ben-Edigbe 2005). In a similar study, Ben-Edigbe, Ferguson (2005) found that a decrease in capacity about $30 \%$ and average speed reduction 40 $\mathrm{km} / \mathrm{h}$. In another study, Ben-Edigbe (2005) and Ben-Edigbe, Ferguson (2009) measured the quantity of service and pavement surface deformation was shown to reduce road capacity by $30 \%$ with an average speed reduction of about $50 \%(20 \mathrm{~km} / \mathrm{h})$. Also in another similar study, Ben-Edigbe (2010) has shown that adverse conditions have significant impacts on the level of road service. He found a significant reduction in speed by up to $50 \%$ and in traffic flow by up to $20 \%$ would result from pavement surface deformations.

Trapezoidal flowrate contraction can be described as "the rate of flowrate forward movement within the constrained chamber of flow $(q)$ - density $(k)$ curve" (Ben-Edigbe et al. 2011). It measures weak road surface conditions are not only recipes for congestion flowrate contractions resulting from highway crashes and they are also characterized by slower capacity loss. To explore flow rate contractions resulting from surface deformations, Ben-Edigbe et al. (2011) tried and found that there is a significant variation in vehicle speeds between "with" and "without" deformation sections. Similarly, Ben-Edigbe, Mashros (2012) found a significant change in vehicle speeds between the "with" and "without" road hump sections. According to study results, they found that highway capacity loss is substantial and it was attributed to road humps spaced at $60 \mathrm{~m}$ intervals. Road capacity reduction was attributed to road surface deformations prevalent per investigated road length per carriageway lane or road humps spaced at $60 \mathrm{~m}$ intervals (Ben-Edigbe et al. 2011).

As can be seen from the previous study results, there is an important need for empirical studies to measure and model the extent of speed reduction and capacity loss caused by pavement surface deformations. Because, they only focused on examining the forming reasons, capacity loss, and speed reduction effects of road surface deformations (Wang 2000, Ben-Edigbe 2005; Ben-Edigbe, Ferguson 2005; Nejad, Zakeri 2011; Ben-Edigbe, Mashros 2012; Aydin et al. 2013). However, they did not examine and model the relation among capacity loss, speed reduction, shockwave and bottleneck forming caused by the surface deformations. In the scope of this study, it is aimed to examine and develop new models to estimate all these relations. For this purpose, the moving bottleneck cases of vehicles caused by the road surface deformations were observed and analysed by considering related parameters.

\section{Description of deformation zones, data collection and evaluation}

\subsection{Study zones}

The effects of pavement surface deformations on capacity drop are significant. These negative effects of surface deformations must be considered when determining flow at deformed road sections. So, within the scope of this study, three DZs were selected on main arterial roads of Tinaztepe Campus, İzmir (Turkey) (Figure 1). Examined road sections consist of divided four-lane (two in each direction) and all have the same characteristics (lane width, lane marking facility etc.). All selected DZs located on the main arterial of Tinaztepe Campus because they have:

- different flow densities on main arterials;

- heavy vehicle (public transit vehicles) effects on pavement surface (5.6\% of total vehicles);

- uninterrupted flow conditions (minimum $400 \mathrm{~m}$ distance to nearest unsignalized intersection);

- facility to take video recordings from high locations;

- urban road conditions ( $50 \mathrm{~km} / \mathrm{h}$ speed limit);

- parking ban on main arterials;

- visible road surface markings;

- road with clear visibility (no curb, barrier etc.). 
DZ-1 and DZ-2 had formed by the heavy vehicle (repeated axle loads) and environmental effects (poor drainage, subbase and base conditions etc.). However, DZ-3 is an artificial deformation and it had formed by the breaking and rapture of some pieces caused by the environmental effects. After breaking and rapture, these pieces were not changed again with a new one by the authorities. Therefore, this artificial deformation gaps on the right lane have encouraged the drivers to use right lane more and it was observed that drivers were more willing to drive to the broken area of the speed bump. Observations showed that drivers generally use the right lane continue to drive traveling pass over the deformation area gaps to avoid the negative effect of a speed bump in the adjacent (left) lane. The summarized information of these DZs is listed in Table 1.

Study zones were separated into three sections with Section A as the upstream end, Section B was the transition section and Section $C$ the downstream end. Sections $A$ and C (before and after DZ) are selected as 300 and 150 $\mathrm{m}$ (enough distance for a clear observation) to allow for survey length, respectively (Figure 2). Section B (on DZ) is selected as $30 \mathrm{~m}$ (before and after $15 \mathrm{~m}$ from deformation point) to examine DZ clearly. Because it was measured that vehicles complete their lane changing behaviours average $30 \ldots 55 \mathrm{~m}$ ranges before the DZs to avoid the negative effects of deformation in low traffic flow conditions (Figure 2).

a)

b)

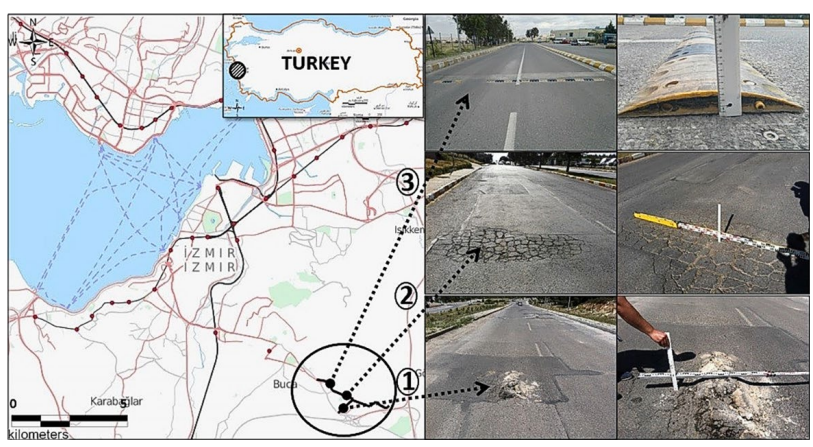

Figure 1. Locations (a) and positions (b) of selected DZs in Izmir (Turkey)

(source: adapted from

(C) OpenStreetMap contributors, CC BY-SA)

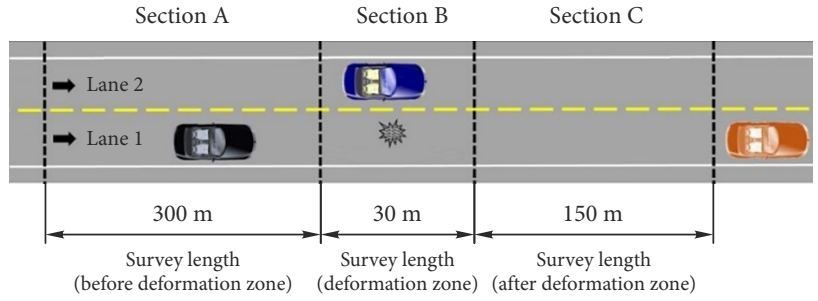

Figure 2. DZ on a two-lane highway

\subsection{Data collection and evaluation}

One of the objectives of this research was to research the effect of pavement surface deformations on uninterrupted traffic flow conditions. The measurement applied here was to determine deformation effect on traffic flow conditions and driving behaviours. Necessary data were recorded for each lane separately. The traffic volume data for each DZ were collected at peak periods during the weekdays. Traffic volume data at $15 \mathrm{~min}$ intervals for the day were collected by using video camera recordings that they were placed at high locations where drivers could not notice. To determine the vehicle speeds, five car camera with GPS tracking system were used as given in Figure 3.

The collected data includes 30 lap movements of 10 different drivers on examined links. Speed profiles of the

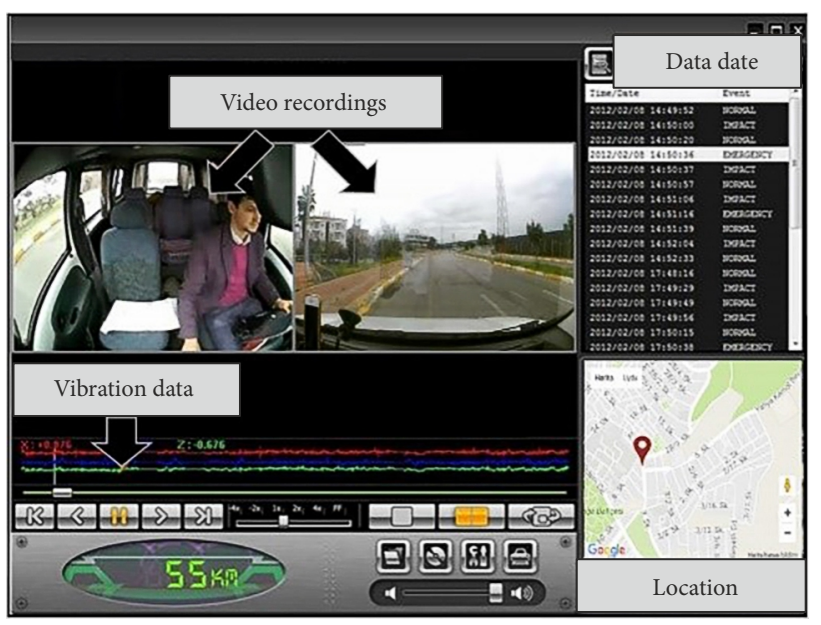

Figure 3. Obtaining of speed and location data by using in-car dashboard camera with GPS tracking system

Table 1. DZs and their geometrical and structural properties

\begin{tabular}{|c|c|c|c|c|c|c|c|c|}
\hline \multirow[b]{2}{*}{$\mathrm{DZ}$} & \multirow[b]{2}{*}{ Lane } & \multirow{2}{*}{$\begin{array}{l}\text { Road width } \\
R_{W}[\mathrm{~m}]\end{array}$} & \multirow{2}{*}{$\begin{array}{c}\text { Deformation } \\
\text { available? }\end{array}$} & \multicolumn{5}{|c|}{ Deformation } \\
\hline & & & & Type $D_{T}$ & $\begin{array}{l}\text { Width } \\
D_{W}[\mathrm{~m}]\end{array}$ & $\begin{array}{l}\text { Length } \\
D_{L}[\mathrm{~m}]\end{array}$ & $\begin{array}{l}\text { Depth or height } \\
D_{D} \text { or } D_{H}[\mathrm{~cm}]\end{array}$ & $\begin{array}{c}\text { Location on road } \\
\text { surface } D_{L}[\mathrm{~m}]\end{array}$ \\
\hline \multirow{2}{*}{1} & left & \multirow{2}{*}{9.6} & yes & swelling & 1 & 1.65 & $16 \cdot D_{H}$ & $5.2 \ldots 6.2$ \\
\hline & right & & no & - & - & - & - & - \\
\hline \multirow[b]{2}{*}{2} & left & \multirow[b]{2}{*}{9.6} & no & - & - & - & - & - \\
\hline & right & & yes & $\begin{array}{l}\text { high severity alligator, } \\
\text { cracking and pothole }\end{array}$ & 2 & 1.5 & $6.7 \cdot D_{D}$ & $1 \ldots 3$ \\
\hline \multirow{2}{*}{3} & left & \multirow{2}{*}{9.6} & yes & fully block speed bump & 0.3 & 5 & $3.5 \cdot D_{H}$ & $1.9 \ldots 2.5$ \\
\hline & right & & yes & partial speed bump & 0.3 & 0.6 & $3.5 \cdot D_{H}$ & $4.2 \ldots 9$ \\
\hline
\end{tabular}


vehicles resulted from the deformations were obtained by the way of GPS devices, which has less than $1 \mathrm{~s}$ delay error. Lane widths and lengths of DZs were measured with steel tape meter. All data were collected during weekdays, under dry and open weather conditions. Within the research total, 1040 vehicles were successfully observed and flow-density $(q-k)$ curves obtained as given in Figure 4 .

Figure 4 shows the $q-k$ curves of each DZ for right and left lane before and on the deformed pavement surface. As shown in Figures $4 \mathrm{a}, 4 \mathrm{~b}$ on DZ-1 right lane $380 \mathrm{veh} / \mathrm{h}$ and on DZ-1 left lane $616 \mathrm{veh} / \mathrm{h}$ capacity loss were observed. Examining Figures $4 \mathrm{a}, 4 \mathrm{~b}$ shows that capacity loss on left lane is higher than right lane. Because deformation

a)

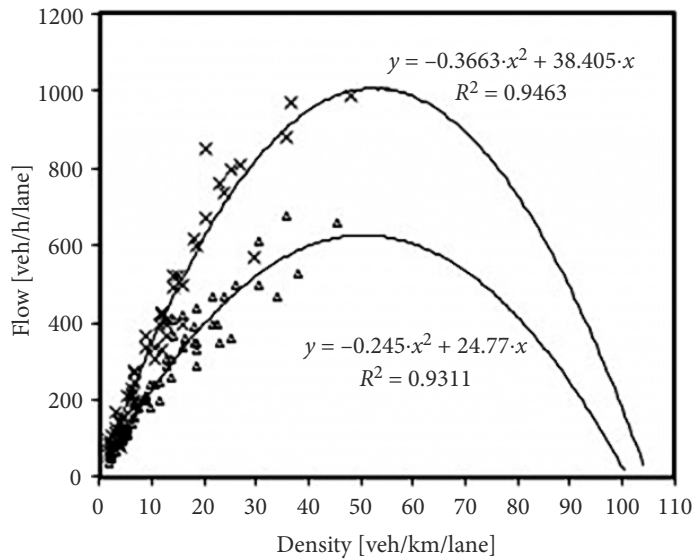

c)

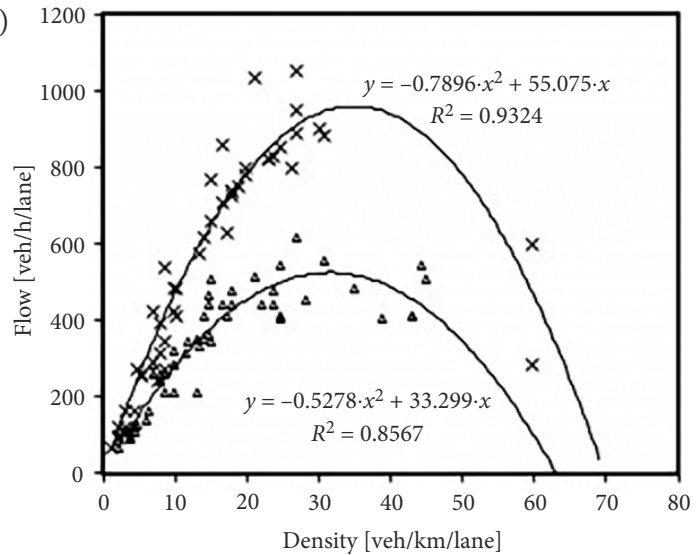

e)

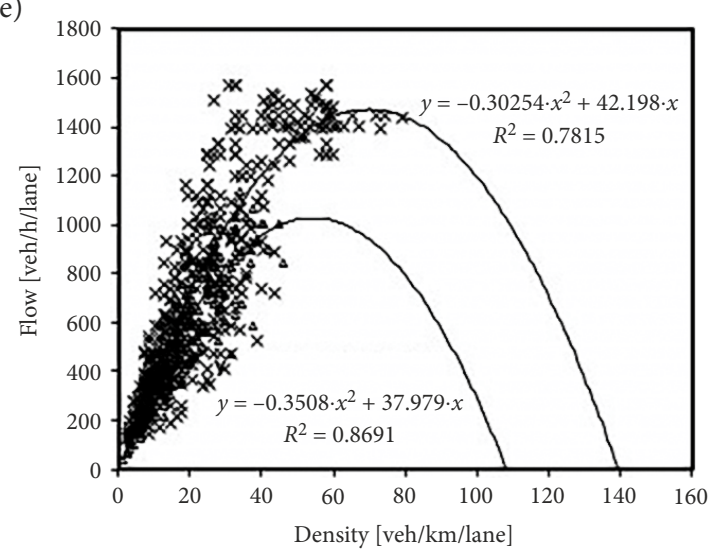

is located on left lane and it was seen that vehicles on left lane are changing their lanes to avoid the negative effect of the deformed pavement surface. The capacity drop was calculated $435 \mathrm{veh} / \mathrm{h}$ in the DZ-2 right lane and $158 \mathrm{veh} / \mathrm{h}$ in DZ-2 left lane (Figures 4c, 4d). According to obtained result, it was seen that capacity drop is higher in the deformed lane. The capacity drop on DZ-3 is observed quite significant. Artificial deformation on DZ-3 consists of two parts. First of these is the part located on $190 \ldots 250 \mathrm{~cm}$ ranges of the road and the second is on $400 \ldots 900 \mathrm{~cm}$ range. As can be seen from Figures $4 \mathrm{e}, 4 \mathrm{f}$ due to continuous deformation along the left lane, vehicles preferred the right lane more. Although the height of deformation
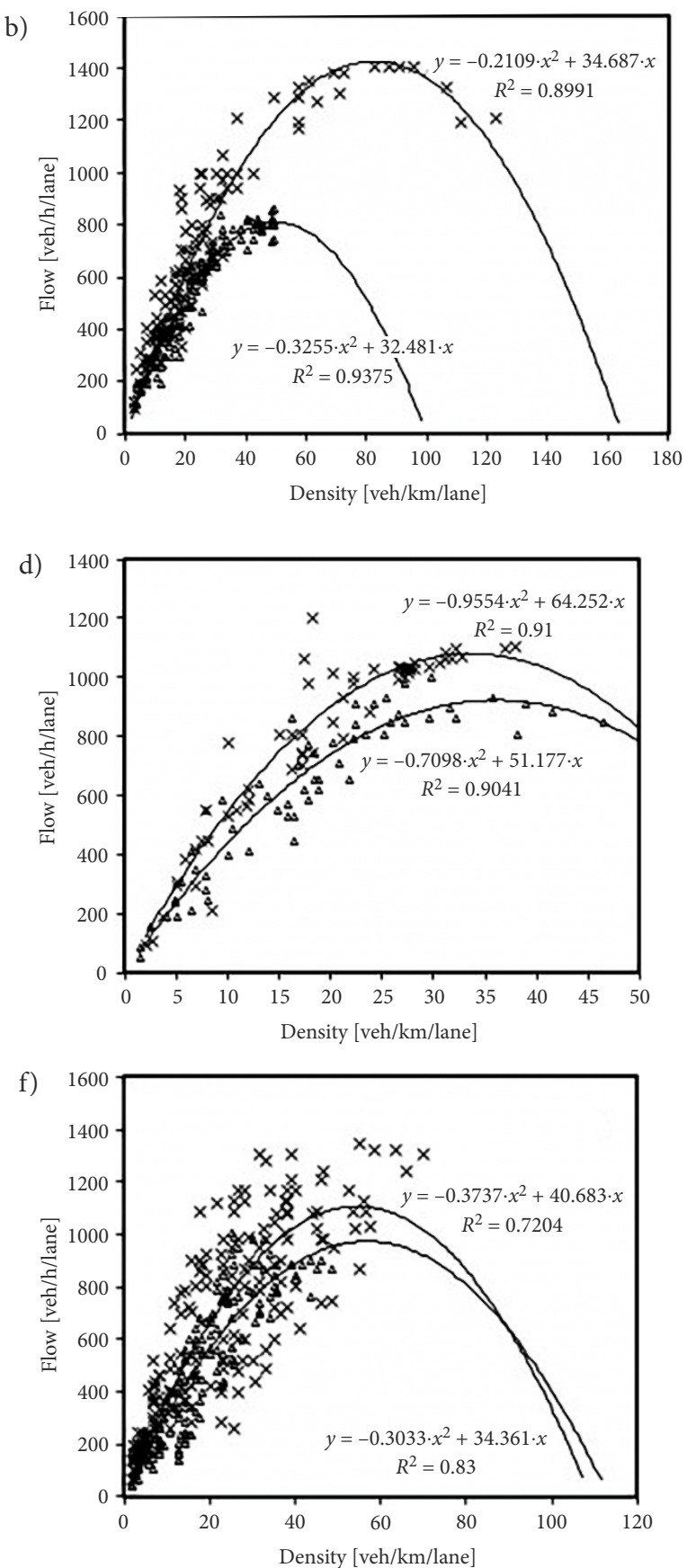

Figure 4. Flow-density $(q-k)$ curves of three DZ for right and left lane before deformed and on the deformed surface 
is such small value as $3.5 \mathrm{~cm}$, experiencing such impact along all left lane and part of the right lane makes drivers prefer the option more comfortable and less harmful for mechanical parts of the vehicle. This artificial interval on the right lane gives drivers more advantages. From the observations, it was concluded that drivers generally use that right lane continue to drive traveling pass over the DZ intervals. In addition, observation findings showed that if there is no vehicle in the adjacent lane, vehicles are more willing to change their lane to avoid the deformation effect $(86.8 \%)$. According to analysis results, it was seen that capacity drop was $444 \mathrm{veh} / \mathrm{h}$ on DZ-3 right lane and $134 \mathrm{veh} / \mathrm{h}$ on DZ-3 left lane. It was plausible to assume that the partially located deformations on pavement surface have less impact on capacity drop according to fully located artificial deformations. In addition, descriptive statistics of speeds for before, on and after DZs and speed distributions of vehicles before and on deformed road sections were given in Table 2 and Figures $5 \mathrm{a}, 5 \mathrm{~b}$ and $5 \mathrm{c}$, respectively.

As can be seen from Table 2 and Figure 5, the speed distribution of vehicles is close to each other on deformed zones for both lanes. It shows that pavement surface deformation on a lane not only effect deformed lane but also effects non-deformed adjacent lane too. Figure 5 also shows that the maximum speed reduction was observed on DZ-2 (20.5\%). It means that DZ-2 the most effective deformation type (high severity alligator, cracking and pothole) on speed reduction behaviour of the vehicles.

Table 2. Descriptive statistics of vehicle speeds before-on-after DZs

\begin{tabular}{|c|l|c|c|}
\hline \multirow{2}{*}{$\mathrm{DZ}$} & $\begin{array}{c}\text { Vehicle } \\
\text { location }\end{array}$ & $\begin{array}{c}\text { Average speed } \\
V_{\text {avg }}[\mathrm{km} / \mathrm{h}]\end{array}$ & $\begin{array}{c}\text { Standard deviation } \sigma \\
{[\mathrm{km} / \mathrm{h}]}\end{array}$ \\
\hline \multirow{4}{*}{1} & before DZ & 35.0 & 4.3 \\
\cline { 2 - 4 } & on DZ & 32.4 & 5.6 \\
\cline { 2 - 4 } & after DZ & 39.4 & 6.0 \\
\hline \multirow{3}{*}{2} & before DZ & 45.8 & 5.0 \\
\cline { 2 - 4 } & on DZ & 38.0 & 4.1 \\
\cline { 2 - 4 } & after DZ & 41.6 & 4.6 \\
\hline \multirow{3}{*}{3} & before DZ & 33.2 & 4.9 \\
\cline { 2 - 4 } & on DZ & 28.3 & 5.2 \\
\cline { 2 - 4 } & after DZ & 40.8 & 5.9 \\
\hline
\end{tabular}

\section{Data analysis and findings}

\subsection{Empirical capacity, speed and density estimation approach}

Road capacity can be defined as "the maximum hourly rate at which vehicles can reasonably be expected to traverse a point or uniform section of a lane or road during a given time period under prevailing road, traffic and control conditions" (TRB 2004, 2010). In this study, investigated road sections were at bottleneck capacity; therefore, the $q-k$ relationship was used to calculate average capac- a)

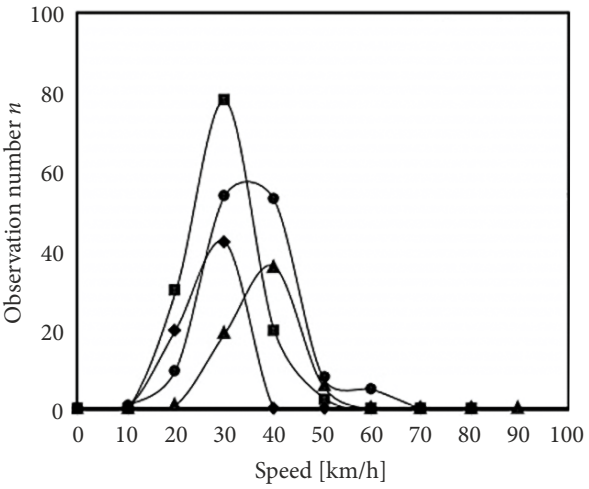

b)

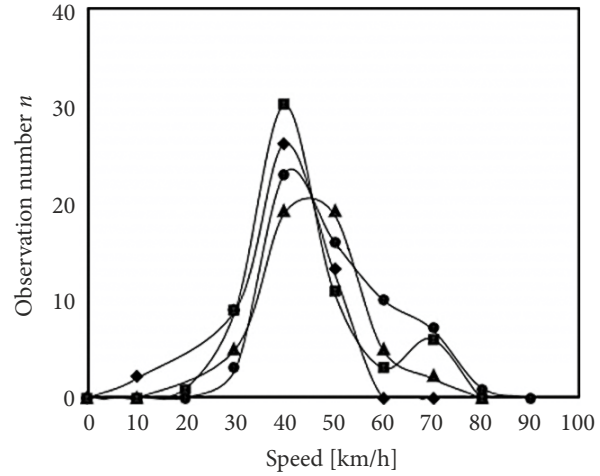

c)

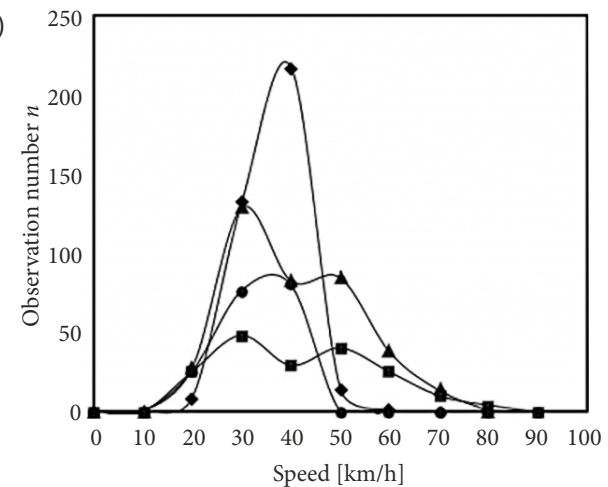

$\longrightarrow$ Left lane before deformation $\longrightarrow$ Right lane before deformatio
$\longrightarrow$ Left lane on deformation
$\longrightarrow$ Right lane on deformation

Figure 5. Speed distributions of vehicles on DZ: a - before DZ; b - on DZ; c - after DZ

ity with trapezoidal flowrate contractions. Before proceeding with the $q-k$ relationship, the following relationship among speed, flow and density needs to be presented and described:

$$
\begin{aligned}
& q=u \cdot k ; \\
& u=\frac{q}{k} ; \\
& k=\frac{q}{u},
\end{aligned}
$$

where: $q$ is traffic flow [veh/h]; $u$ is vehicle speed $[\mathrm{veh} / \mathrm{h}]$; $k$ is density [veh/lane $/ \mathrm{km}$ ].

The flow is shown to be equivalent to the product of speed $u$ and density $k$. It can be calculated from the Equation (1), $q$ is apparently equalled to zero when $k$ is zero (Ben-Edigbe, Mashros 2012). As density (and flow) 
increases, speeds are reduced until flow is maximum, and speed and density approach their optimum values $\left(u \rightarrow u_{0}\right.$ and $k \rightarrow k_{0}$ ). Further increases in density result in lower speeds (and lower flows) until density reaches its maximum value $k_{j}$ and correspondingly speed (and flow) approach zero $(u \rightarrow 0$ and $q \rightarrow 0)$. In addition, the $q-k$ relationship has been shown by Van Arem et al. (1994) and Minderhoud et al. (1997) to have a quadratic function. In this function, $k$ - control parameter and $q$ - objective function (Ben-Edigbe, Mashros 2012), as shown in Equation (2):

$$
q=-x_{0}+x_{1} \cdot k-x_{2} \cdot k^{2},
$$

where: $x_{0}$ is a constant; $x_{1}, x_{2}$ are coefficients $\left(x_{0}\right.$ defines road density, $x_{1} \cdot k$ defines vehicle speed while $x_{2} \cdot k^{2}$ defines traffic flow).

Equation (2) has to be $\leq 0$ for coefficients $x_{2}$ and $x_{0}$, and $x_{1}$ has to be $>0$ to provide the concavity shape of the flowdensity curve. Additionally, flow rates are constrained within finite density boundaries $\left(0\right.$ and $\left.k_{j}\right)$ in order not to violate. The $u-k$ relationship helps to understand system properties of various traffic conditions. If speeds of vehicles and density of roads (Equation (3)) are plugged into Equation (1); the obtained second-degree polynomial Equation (4) can then be used to predict the capacity of the examined road section.

$$
u=x_{1}-x_{2} \cdot k
$$

in this case, $u-k$ curve has a negative linear function by plugging Equation (3) into Equation (1), flow equation can also be written as:

$$
q=x_{1} \cdot k-x_{2} \cdot k^{2} \text {. }
$$

Consider Equation (2) $=$ Equation (4), therefore:

$$
x_{1} \cdot k-x_{2} \cdot k^{2}=-x_{0}+x_{1} \cdot k-x_{2} \cdot k^{2} \text {. }
$$

Hence, constant $x_{0}=0$. When density is at zero $(k=0)$ the maximum flow $q_{\max }$ value can be reachable, and when maximum density $k_{\max }$ is obtained, the flow becomes zero or jam. Consider that:

$$
\begin{aligned}
& x_{2}=\frac{x_{1}}{k_{j}} \rightarrow \\
& u=x_{1}-\frac{x_{1}}{k_{j}} \cdot k \rightarrow \\
& q=x_{1} \cdot k-\frac{x_{1}}{k_{j}} \cdot k^{2} ;
\end{aligned}
$$

a)

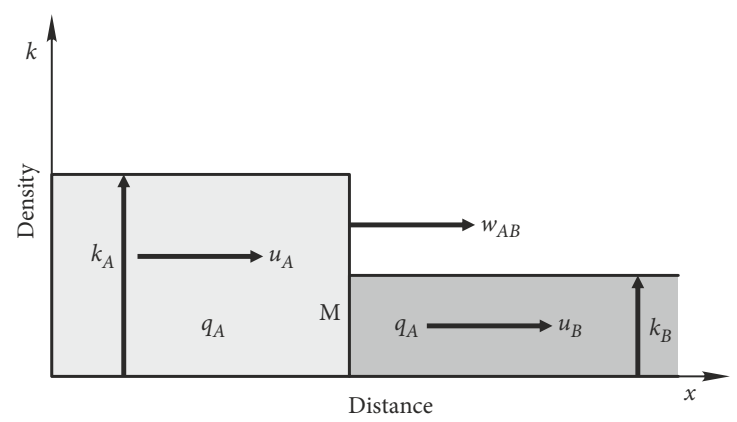

$$
\frac{\partial q}{\partial k}=x_{1}-2 \cdot\left(\frac{x_{1}}{k_{j}}\right) \cdot k .
$$

Critical density:

$$
k_{c r t}=\frac{x_{1}}{2 \cdot\left(\frac{x_{1}}{k_{j}}\right)},
$$

then:

$$
u=x_{1}-\frac{x_{1}}{k_{j}} \cdot\left(\frac{x_{1}}{2 \cdot \frac{x_{1}}{k_{j}}}\right),
$$

apacity:

$$
Q=x_{1} \cdot k-\frac{x_{1}}{k_{j}} \cdot\left(\frac{x_{1}}{2 \cdot\left(\frac{x_{1}}{k_{j}}\right)}\right) .
$$

Hence, road capacity was estimated by using Equation (6).

\subsection{Shockwave and bottleneck estimation approach}

A shockwave is defined as the motion or propagation of a change in density and traffic flow. Consider a road with two different traffic densities at time $t=0$ for two distinct density of traffic $k_{A}$ and $k_{B}$ along with a straight highway section. The transition from one density to another takes place at point $\mathrm{M}$, which has a speed of $w_{A B}$. The movement of traffic flow and different densities on Sections A, B and $\mathrm{C}$ by the line separating can be represented in Figures $6 \mathrm{a}$ and $6 \mathrm{~b}$, respectively. In addition, the passage of the traffic waves through the bottleneck area is shown in Figure 6b.

The speed of shockwave $w_{A B}$ can be defined as the change from case (Section A) to case (Section B) is the slope of this lane. If this slope is positive, shockwave spreads forwards with respect to a stationary observer. If it is negative, the shockwave spreads backward. We can calculate shockwave speed as follows (Gazis 2002; Gerlough, Huber 1975; Richards 1956; Cho 2013).

In time $t$ the vehicle numbers $N$ crossing the dividing line $\mathrm{M}$ is:

$$
N=U_{r A} \cdot k_{A} \cdot t=U_{r B} \cdot k_{B} \cdot t,
$$

where: $U_{r A}=u_{A}-w_{A B}$ is speed of vehicles in zone $\mathrm{A}$ relative to the moving line $M\left(u_{A}\right.$ is space mean speed

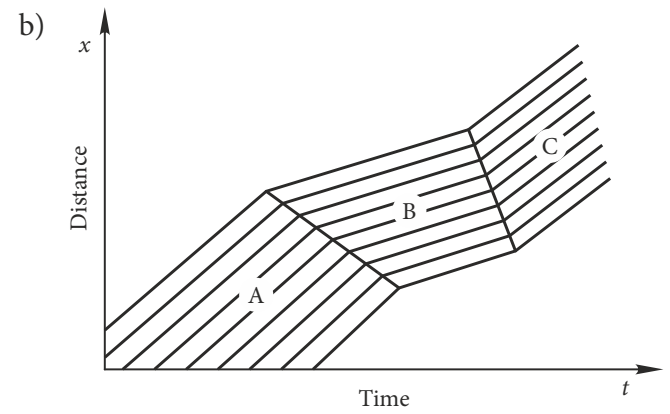

Figure 6. The movement (a) of different traffic densities and speed changes (b) of a moving platoon (Gazis 2002) 
of vehicles in Section A); $U_{r B}=u_{B}-w_{A B}$ is the speed of vehicles in Section $B$ relative to the moving line $M\left(u_{B}\right.$ is space mean speed of vehicles in zone B).

Equation (7) leads to relationship Equation (8):

$$
\left(u_{A}-w_{A B}\right) \cdot k_{A}=\left(u_{B}-w_{A B}\right) \cdot k_{B} \text {. }
$$

Equation (8) is a restatement of the principle of conversation of vehicles and can be rewritten as Equation (9):

$$
u_{B} \cdot k_{B}-u_{A} \cdot k_{A}=w_{A B} \cdot\left(k_{B}-k_{A}\right) \text {. }
$$

Using the fundamental $u-k-q$ relationship among speed $u$, flow $q$ and density $k, q=u \cdot k \rightarrow w_{A B}$ can be rewritten as Equation (10):

$$
w_{A B}=\frac{q_{B}-q_{A}}{k_{B}-k_{A}} .
$$

However, Equation (10) describes a shockwave case when traffic meets a bottleneck, as showed in Figures 6a and $6 \mathrm{~b}$ where the flow $q_{B}$ indicates downstream and the flow $q_{A}$ indicates upstream. Furthermore, it may be observed that the derivation of Equation (10) does not need the presence of a unique flow-density $(q-k)$ relationship. It can be derived from Figure 6b, and only assumes that the presence of two possible steady-case flow condition, $\left(q_{A}, k_{A}\right)$ and $\left(q_{B}, k_{B}\right)$. The shockwave speed can also be observed graphically from the Figure $6 \mathrm{~b}$ with the slope of the connecting line between these two case (A and B). $w_{A B}$ is the fundamental equation for the speed of "kinematic" waves in a traffic flow according to Lighthill and Whitham (1955a, 1955b). It can be derived on geometric grounds from Figure. 6b, and only assumes the existence of two possible steady case traffic flow conditions, $\left(q_{A}, k_{A}\right)$ and $\left(q_{B}, k_{B}\right)$.

A bottleneck is a stretch of a road section where the capacity is less than from upstream and downstream. $q-k$ curves at various points within the bottleneck is shown in Figure 7. Current figure represents that how the speed

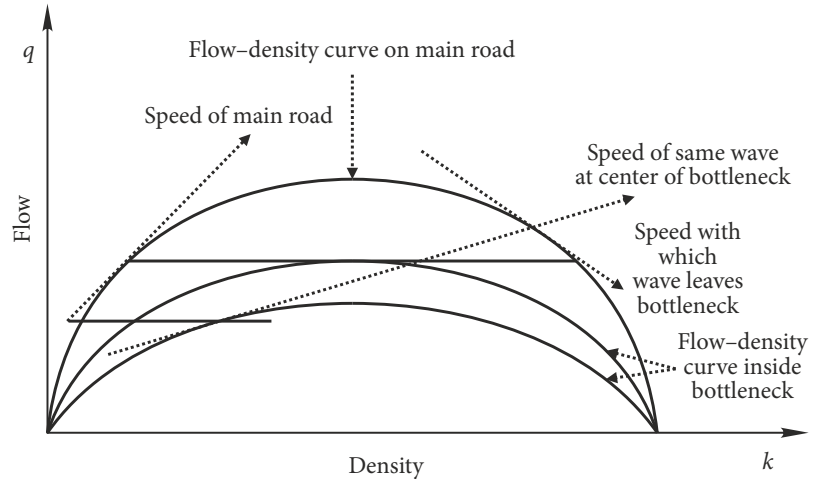

Figure 7. Changes in flow-density $(q-k)$ curve at a bottleneck (Richards 1956)

of the flow suddenly drops as the bottleneck is reached. It also shows the passage of the traffic waves through the bottleneck area.

\subsection{Development and analysis of model parameters}

Study steps for predicting trapezoidal flow contractions and road capacities can be expressed as given diagram (Figure 8).

A summary of the suggested $q, u$ and $\mathrm{k}$ model equations for road Sections A, B and C obtained by using $q-k$ curve equation were given in Table 3.

However, using $q-k$ relationship, capacity loss values [\%] were calculated for three DZs and each lane, separately. Also using critical density $k_{c r t}$ values, optimum speed $u_{0}$ values were calculated. A sample computing for road capacity loss [\%] is given below for DZ-1 right lane:

before DZ:

$$
\begin{aligned}
& q_{A}=-0.3663 \cdot k^{2}+38.405 \cdot k ; \\
& \frac{\partial q}{\partial k}=2 \cdot(-0.3663)+38.405=0 ; \\
& k_{c r t}=52 \mathrm{veh} / \mathrm{km} ;
\end{aligned}
$$

Table 3. $q, u$ and $k$ calculation models for before bottleneck, at the bottleneck and after bottleneck road sections

\begin{tabular}{|c|c|c|c|c|c|c|c|c|}
\hline \multirow{2}{*}{ DZ } & \multirow{2}{*}{ Lane } & \multicolumn{2}{|c|}{ Density $[\mathrm{veh} / \mathrm{km} / \mathrm{lane}]$} & \multicolumn{2}{c|}{ Speed $[\mathrm{km} / \mathrm{h}]$} & \multicolumn{2}{c|}{ Flow $[\mathrm{veh} / \mathrm{h}]$} \\
\cline { 2 - 8 } & $k_{A}$ & $k_{B}$ & $k_{C}$ & $u_{A, C}$ & $u_{B}$ & $q_{A, C}$ & $q_{B}$ \\
\hline \multirow{2}{*}{1} & \multirow{2}{*}{ right } & 20 & 51 & 85 & $-0.3663 \cdot k_{A, C}+38.405$ & $-0.2450 \cdot k_{B}+24.771$ & $\frac{38.405 \cdot u_{A, C}-u_{A, C}^{2}}{0.3663}$ & $\frac{24.77 \cdot u_{B}-u_{B}^{2}}{0.245}$ \\
\cline { 2 - 8 } & left & 28 & 50 & 136 & $-0.2109 \cdot k_{A, C}+34.687$ & $-0.3255 \cdot k_{B}+32.481$ & $\frac{34.687 \cdot u_{A, C}-u_{A, C}^{2}}{0.2109}$ & $\frac{32.481 \cdot u_{B}-u_{B}^{2}}{0.3255}$ \\
\hline \multirow{2}{*}{2} & \multirow{2}{*}{ right } & 11 & 32 & 58 & $-0.7896 \cdot k_{A, C}+55.075$ & $-0.5278 \cdot k_{B}+33.299$ & $\frac{55.075 \cdot u_{A, C}-u_{A, C}^{2}}{0.7896}$ & $\frac{33.299 \cdot u_{B}-u_{B}^{2}}{0.5278}$ \\
\cline { 2 - 8 } & left & 21 & 36 & 46 & $-0.9554 \cdot k_{A, C}+64.252$ & $-0.7098 \cdot k_{B}+51.177$ & $\frac{64.252 \cdot u_{A, C}-u_{A, C}^{2}}{0.9554}$ & $\frac{51.177 \cdot u_{B}-u_{B}^{2}}{0.7098}$ \\
\hline \multirow{2}{*}{3} & right & 32 & 54 & 108 & $-0.3025 \cdot k_{A, C}+42.198$ & $-0.3508 \cdot k_{B}+37.979$ & $\frac{42.198 \cdot u_{A, C}-u_{A, C}^{2}}{0.3025}$ & $\frac{37.979 \cdot u_{B}-u_{B}^{2}}{0.3508}$ \\
\cline { 2 - 8 } & left & 36 & 57 & 73 & $-0.3737 \cdot k_{A, C}+40.683$ & $-0.3033 \cdot k_{B}+34.361$ & $\frac{40.683 \cdot u_{A, C}-u_{A, C}^{2}}{0.3737}$ & $\frac{34.361 \cdot u_{B}-u_{B}^{2}}{0.3033}$ \\
\hline
\end{tabular}


$q_{A}=-0.3663 \cdot 52^{2}+38.405 \cdot 52 ;$

$q_{\mathrm{A}}=1006 \mathrm{veh} / \mathrm{h}$;

$u_{0} \approx 19.3 \mathrm{~km} / \mathrm{h}$;

on DZ:

$q_{B}=-0.245 \cdot k^{2}+24.77 \cdot k$;

$\frac{\partial q}{\partial k}=2 \cdot(-0.245)+24.77=0$;

$k_{c r t}=51 \mathrm{veh} / \mathrm{km}$;

$q_{B}=-0.245 \cdot 51^{2}+24.77 \cdot 51 ;$

$q_{B}=626 \mathrm{veh} / \mathrm{h}$;

$u_{0} \approx 12.3 \mathrm{~km} / \mathrm{h}$.

According to given analysis, capacity loss $Q_{\text {loss }}$ was calculated as $37.8 \%$ [veh/h/lane]. Obtained optimum speed $u_{0}$ values were derived from calculated capacity values and they shows differences for each lane according to the relation among $u, q$ and $k$ at examined road sections. Therefore, speeds of shockwaves $w_{A B}$ were calculated for all examined zones and lanes, separately and a samplecomputing for $w_{A B}$ is given below for DZ-1 right and left lane:

DZ-1 right lane:

$$
w_{A B_{R}}=\frac{q_{A B_{R}}-q_{A B_{R}}}{q_{A B_{R}}-w_{A B_{R}}} ;
$$

$$
\begin{aligned}
& w_{A B}=\frac{626-1006}{51-20} ; \\
& w_{A B}=-12.3 \mathrm{~km} / \mathrm{h} ;
\end{aligned}
$$

DZ-1 left lane:

$$
\begin{aligned}
& w_{A B_{L}}=\frac{q_{A B_{L}}-q_{A B_{L}}}{q_{A B_{L}}-w_{A B_{L}}} ; \\
& w_{A B}=\frac{810-1426}{50-28} ; \\
& w_{A B}=-28 \mathrm{~km} / \mathrm{h} .
\end{aligned}
$$

Shockwave speeds for DZ-1 right and left lane were calculated as -12.3 and $-28 \mathrm{~km} / \mathrm{h}$, respectively. This result shows that shockwave speeds have negative values and it means that shocks propagate backward. Summary of analysis findings for all examined parameters is shown in Table 4.

The results in Table 4 shows that if vehicles' speeds increase before deformation, the capacity loss will increase because of the large difference in vehicle speed, before and on the DZ. In addition, it can be seen from the Table 4, capacities at road sections "with" surface deformations were quite higher than those at section "without" surface deformations for all examined sections. Maximum traffic flows

\begin{tabular}{|c|c|c|c|c|c|c|c|c|c|c|c|}
\hline \multirow{2}{*}{$\mathrm{DZ}$} & \multirow{2}{*}{ Lane } & \multirow{2}{*}{ Location } & \multirow{2}{*}{$\begin{array}{c}\text { Deformation } \\
\text { available? }\end{array}$} & \multicolumn{4}{|c|}{ Speed $[\mathrm{km} / \mathrm{h}]$} & \multirow{2}{*}{$\begin{array}{l}\text { Capacity } \\
Q[\text { veh/h] }\end{array}$} & \multirow{2}{*}{$\begin{array}{l}\text { Optimal speed } \\
u_{0}[\mathrm{~km} / \mathrm{h}]\end{array}$} & \multirow{2}{*}{$\begin{array}{c}\text { Critical density } \\
k_{c r t}[\mathrm{veh} / \mathrm{km} / \text { lane }]\end{array}$} & \multirow{2}{*}{$\begin{array}{c}\text { Capacity loss } \\
Q_{\text {loss }}[\%]\end{array}$} \\
\hline & & & & $u_{A}$ & $u_{B}$ & $u_{C}$ & $w_{A B}$ & & & & \\
\hline \multirow{4}{*}{1} & \multirow{2}{*}{ right } & before DZ & \multirow{2}{*}{ no } & \multirow{2}{*}{31.1} & \multirow{2}{*}{12.3} & \multirow{2}{*}{7.3} & \multirow{2}{*}{-20.2} & 1006 & 19.3 & 52 & \multirow{2}{*}{37.8} \\
\hline & & on $\mathrm{DZ}$ & & & & & & 626 & 12.3 & 51 & \\
\hline & \multirow{2}{*}{ left } & before DZ & \multirow{2}{*}{ yes } & \multirow{2}{*}{28.8} & \multirow{2}{*}{16.2} & \multirow{2}{*}{6.0} & \multirow{2}{*}{-28.0} & 1426 & 17.4 & 82 & \multirow{2}{*}{43.2} \\
\hline & & on $\mathrm{DZ}$ & & & & & & 810 & 16.2 & 50 & \\
\hline \multirow{4}{*}{2} & \multirow{2}{*}{ right } & before $\mathrm{DZ}$ & \multirow{2}{*}{ yes } & \multirow{2}{*}{46.4} & \multirow{2}{*}{16.4} & \multirow{2}{*}{9.0} & \multirow{2}{*}{-20.7} & 960 & 27.4 & 35 & \multirow{2}{*}{45.3} \\
\hline & & on $\mathrm{DZ}$ & & & & & & 525 & 16.4 & 32 & \\
\hline & \multirow{2}{*}{ left } & before DZ & \multirow{2}{*}{ no } & \multirow{2}{*}{44.2} & \multirow{2}{*}{25.6} & 203 & -105 & 1080 & 31.8 & 34 & \\
\hline & & on $\mathrm{DZ}$ & & & & 20.3 & -10.5 & 923 & 25.6 & 36 & 14.5 \\
\hline & & before DZ & & & & & & 1472 & 21.0 & 70 & \\
\hline 3 & right & on $\mathrm{DZ}$ & yes & 32.5 & 19.0 & 9.5 & -20.2 & 1028 & 19.0 & 55 & 30.2 \\
\hline 3 & left & before DZ & yes & 272 & 171 & 134 & -64 & 1107 & 20.1 & 55 & 121 \\
\hline & IEIt & on $\mathrm{DZ}$ & yes & 27.2 & $1 / .1$ & 13.4 & -0.4 & 973 & 17.1 & 57 & 12.1 \\
\hline
\end{tabular}
$q_{\max }$ were also higher at road sections "without" surface deformations for all examined locations. However, accord-

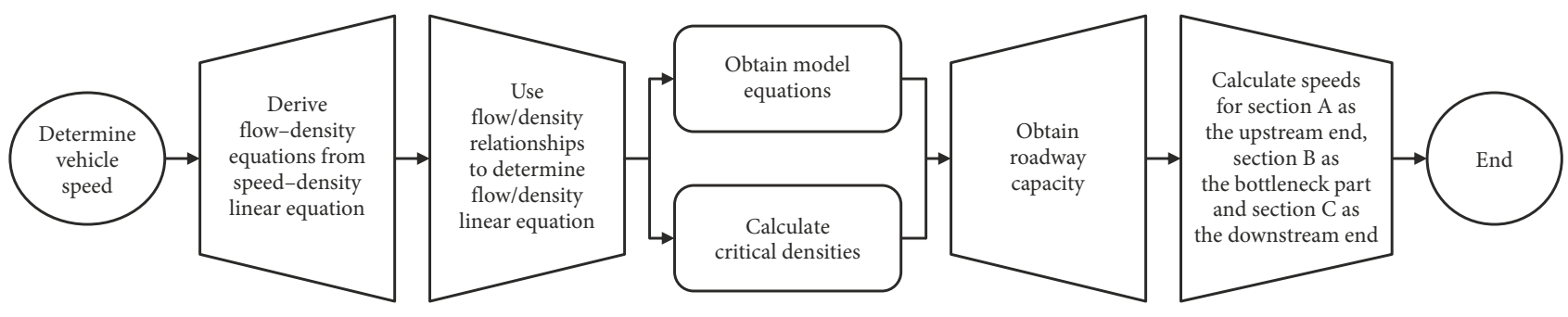

Figure 8. Estimating process of road capacities and trapezoidal flow contractions

Table 4. Estimated parameters for road sections A, B and C 
ing to results, it can be pointed that on a road link with surface deformations, mean traffic flow could be outside of the free flow capacity. Additionally, it can be concluded that surface deformations could cause to capacity loss.

From the analysis results in Table 4, the highest capacity loss is seen on the DZ-2 right lane (45.3\%). In addition, it can be seen from the Table 4 that speeds of vehicles on DZ-1 right lane have higher values than DZ-1 left lane. Because deformation is located on left lane and vehicles are moving on left lane to reduce their speed not expose to the negative effect of deformation. When DZ-2 examined, it is observed that although deformation is located on the right lane, it has not greater effect on speeds of vehicles. It can be said, that deformation has a small effect as shown main reason in here. In DZ-3, artificial deformation (partial speed bumps) on the right lane lets the drivers use right lane more. Drivers generally tend to use the right lane continue to drive traveling pass over the DZ. As a result of high right lane occupancy of vehicles, they were enforcement to slow down. So their approach speed on Section A is observed higher than Section B. When speeds in Section C are examined, queue speeds caused by bottleneck effect of the deformed lane is lower than the queue speeds for a non-deformed adjacent lane. However, DZ-3 right lane gives drivers movement chance at high speeds. So in the DZ-3 right lane contrary results were observed. Also in the DZ-3 right lane, a queue, and a moving bottleneck are seen because of the advantage of a partial speed bump. According to given findings in Table 4, it can be concluded that all deformations have a shockwave effect on deformed and non-deformed adjacent lanes. All calculated shockwaves have negative values. It shows that these shocks propagate backwards and it can cause a query forming to the backward.

\section{Conclusions and discussion}

It is clear from the study that operating performance of roads is affected by pavement surface deformations such as raveling, polishing, rutting, swelling and shoving, potholes, transverse, longitudinal and alligator cracks, etc. The magnitude of pavement surface deformations affects traffic capacity and speed distribution of traffic flow. In addition, this study is based on the hypothesis that pavement surface deformations have a greater impact on capacity loss and speed distribution of vehicles. For the estimation of capacity, the relationship among flow-density $(q-k)$, bottleneck and shockwave analysis methods were used.

In the scope, this study deformed road links were divided three sections. All sections were investigated and the empirical results were examined. According to the obtained results, the numerical findings for all examined road sections were compared between each other. According to obtained results from the relationship between road capacity and surface deformations, and also bottleneck and shockwave analysis methods, the following conclusions can be made:
- pavement surface deformations have a negative effect on traffic flow and level of service;

- flow and density relationship can applicable to predict road capacity;

- if the approach speed is higher, capacity loss also will be higher in deformed road sections;

- capacities for each examined road sections "with" surface deformation were lower than those "without" surface deformation for all cases;

- on a deformed road, average traffic flow rate is lower than non-deformed adjacent road capacity;

- there are significant reductions in capacity relatively by up to 44 and $26 \%$ and in speed relatively by up to 51 and $49 \%$ would result from surface deformation on deformed lanes and non-deformed adjacent lanes;

- there are significant reductions in capacity relatively by up to 30 and $12 \%$ and in speed relatively by up to 41 and 56\% would result from partial and full artificial deformed lanes;

- deformations cause backward shockwaves and query forming on both deformed and non-deformed adjacent lanes.

This study showed that speed-flow $(u-q)$ functions can be estimated by dividing the curve into the free flow and congested sections and applying suitable polynomial function. In addition, the study is conducted for determination of the surface deformation effects on multi-lane roads considering a very limited data. Future studies aim to collect data from various and more as both through a video camera, GPS and ITS devices. Simultaneous utilization of these devices in flows with different intensities would give better speed, and acceleration/deceleration data. For the upcoming studies, on a deformed road can be investigated especially in the light of more extended data gathered from the urban and rural roads in nondeveloping and developing countries. By conducting such studies, traffic flow models functions presented in the paper can be verified and improved.

\section{References}

Akgüngör, A. P.; Demirel, A. 2008. Investigating urban trafficbased noise pollution in the city of Kirikkale, Turkey, Transport 23(3): 273-278.

https://doi.org/10.3846/1648-4142.2008.23.273-278

Akgüngör, A. P.; Doğan, E. 2009. An artificial intelligent approach to traffic accident estimation: Model development and application, Transport 24(2): 135-142.

https://doi.org/10.3846/1648-4142.2009.24.135-142

Aydın, M. M. 2012. Çok şeritli yollarda sürücü şerit seçim davranışlarının modellenmesi. Yüksek Lisans Tezi. Dokuz Eylül Universitesi, Fen Bilimleri Enstitüsü, Izmir, Turkey. 146 s. (in Turkish). Available from Internet:

http://acikerisim.deu.edu.tr/xmlui/handle/12345/7778

Aydin, M. M.; Topal, A. 2016. Effect of road surface deformations on lateral lane utilization and longitudinal driving behaviours, Transport 31(2): 192-201.

https://doi.org/10.3846/16484142.2016.1193049 
Aydın, M. M.; Topal, A.; Tanyel, S. 2013. Çok şeritli yollarda yol yüzey bozukluklarının sürücü davranışları üzerindeki etkisinin incelenmesi, in TMMOB 10: Ulaştırma Kongresi, 25-27 Eylül 2013, İzmir, Turkey, 413-425 (in Turkish).

Aydın, M. M.; Yildirim, M. S.; Karpuz, O.; Ghasemlou, K. 2014. Modeling of driver lane choice behaviour with artificial neural networks (ANN) and linear regression (LR) analysis on deformed roads, Computer Science \& Engineering: an International Journal 4(1): 47-57.

https://doi.org/10.5121/cseij.2014.4105

Ben-Edigbe, J. 2005. Influence of Pavement Distress on Capacity Loss and Their Implications for PCE. PhD Thesis. University of Strathclyde, Glasgow, Scotland.

Ben-Edigbe, J. 2010. Assessment of speed-flow-density functions under adverse pavement condition, International Journal of Sustainable Development and Planning 5(3): 238-252.

https://doi.org/10.2495/SDP-V5-N3-238-252

Ben-Edigbe, J. 2016. Computing flexible pavement distress zone travel time differentials on multilane highway, International Journal of Applied Engineering Research 11(14): 8340-8344.

Ben-Edigbe, J.; Ferguson, N. 2005. Extent of capacity loss resulting from pavement distress, Proceedings of the Institution of Civil Engineers - Transport 158(1): 27-32. https://doi.org/10.1680/tran.2005.158.1.27

Ben-Edigbe, J.; Ferguson, N. 2009. Qualitative road service reduction resulting from pavement distress, in Urban Transport XV: Urban Transport and the Environment, 22-24 June 2009, Bologna, Italy.

Ben-Edigbe, J.; Mashros, N. 2012. Extent of highway capacity loss resulting from road humps, International Journal of Engineering and Technology 4(2): 121-125. https://doi.org/10.7763/IJET.2012.V4.331

Ben-Edigbe, J.; Mashros, N.; Minhans, A. 2011. Exploration of trapezoidal flowrate contractions resulting from pavement distress, Journal of Emerging Trends in Engineering and Applied Sciences 2(2): 351-354.

Brown, S. F. 1995. Practical test procedures for mechanical properties of bituminous materials, Proceedings of the Institution of Civil Engineers - Transport 111(4): 289-297.

https://doi.org/10.1680/itran.1995.28031

Chen, J.; Shi, Z.; Hu, Y.; Yu, L.; Fang, Y. 2013. An extended macroscopic model for traffic flow on a highway with slopes, International Journal of Modern Physics C 24(9): 1350061. https://doi.org/10.1142/S0129183113500617

Chen, J.; Peng, Z.; Fang, Y. 2014. Effects of car accidents on three-lane traffic flow, Mathematical Problems in Engineering 2014: 413852. https://doi.org/10.1155/2014/413852

Cho, S. 2013. Revisiting shock wave theory, Proceedings of the Institution of Civil Engineers - Transport 166(6): 354-361. https://doi.org/10.1680/tran.11.00032

Dell'Acqua, G.; De Luca, M.; Lamberti, R. 2011. Indirect skid resistance measurement for porous asphalt pavement management, Transportation Research Record: Journal of the Transportation Research Board 2205: 147-154.

https://doi.org/10.3141/2205-19

Dell'Acqua, G.; De Luca, M.; Prato, C. G.; Prentkovskis, O.; Junevičius, R. 2016. The impact of vehicle movement on exploitation parameters of roads and runways: a short review of the special issue, Transport 31(2): 127-132.

https://doi.org/10.3846/16484142.2016.1201912

Dell'Acqua, G.; Russo, F. 2011. Road performance evaluation using geometric consistency and pavement distress data, Transportation Research Record: Journal of the Transportation Research Board 2203: 194-202. https://doi.org/10.3141/2203-24
Gazis, D. C. 2002. Traffic Theory. Springer US. 259 p. https://doi.org/10.1007/b101918

Gerlough, D. L.; Huber, M. J. 1975. Traffic Flow Theory. Monograph. Special Report 165. Transportation Research Board (TRB), Washington, DC, US. 233 p. Available from Internet: http://onlinepubs.trb.org/onlinepubs/sr/sr165/165.pdf

Ghasemlou, K.; Aydın, M. M.; Yıldırım, M. S. 2016. An investigation on lane blockage effects at signalized intersections, International Journal for Traffic and Transport Engineering 6(3): 289-302. https://doi.org/10.7708/ijtte.2016.6(3).05

Jiang, Y. 1999. Traffic Characteristics and Estimation of Traffic Delays and User Costs at Indiana Freeway Work Zones. Final Report FHWA/INDOT/SPR-2121. Indiana Department of Transportation (INDOT), US. Available from Internet: https://rosap.ntl.bts.gov/view/dot/5034

Jiang, Y.; Li, S. 2002. Measuring and analyzing vehicle position and speed data at work zones using global positioning systems, ITE Journal 72(3): 48-53.

Kurata, S.; Nagatani, T. 2003. Spatio-temporal dynamics of jams in two-lane traffic flow with a blockage, Physica A: Statistical Mechanics and its Applications 318(3-4): 537-550. https://doi.org/10.1016/S0378-4371(02)01376-6

Lee, H. D.; Kim, J. J. 2005. Development of a Manual Crack Quantification and Automated Crack Measurement System. Project No 457. Final Report. University of Iowa, US. 21 p. Available from Internet: http://publications.iowa.gov/2423/1/tr457.pdf

Lighthill, M. J.; Whitham, G. B. 1955a. On kinematic waves I. Flood movement in long rivers, Proceedings of the Royal Society of London. Series A. Mathematical and Physical Sciences 229(1178): 281-316. https://doi.org/10.1098/rspa.1955.0088

Lighthill, M. J.; Whitham, G. B. 1955b. On kinematic waves II. A theory of traffic flow on long crowded roads, Proceedings of the Royal Society of London. Series A. Mathematical and Physical Sciences 229(1178): 317-345.

https://doi.org/10.1098/rspa.1955.0089

Minderhoud, M. M.; Botma, H.; Bovy, P. H. L. 1997. Assessment of roadway capacity estimation methods, Transportation Research Record: Journal of the Transportation Research Board 1572: 59-67. https://doi.org/10.3141/1572-08

Nejad, F. M.; Zakeri, H. 2011. A comparison of multi-resolution methods for detection and isolation of pavement distress, $E x$ pert Systems with Applications 38(3): 2857-2872.

https://doi.org/10.1016/j.eswa.2010.08.079

Prentkovskis, O.; Tretjakovas, J.; Švedas, A.; Bieliatynskyi, A.; Daniūnas, A.; Krayushkina, K. 2012. The analysis of the deformation state of the double-wave guardrail mounted on bridges and viaducts of the motor roads in Lithuania and Ukraine, Journal of Civil Engineering and Management 18(5): 761-771. https://doi.org/10.3846/13923730.2012.731252

Prentkovskis, O.; Beljatynskij, A.; Juodvalkienè, E.; Prentkovskienè, R. 2010. A study of the deflections of metal road guardrail post, The Baltic Journal of Road and Bridge Engineering 5(2): 104-109. https://doi.org/10.3846/bjrbe.2010.15

Richards, P. I. 1956. Shockwaves on the highway, Operations Research 4(1): 42-51. https://doi.org/10.1287/opre.4.1.42

Strazdins, G.; Mednis, A.; Kanonirs, G.; Zviedris, R.; Selavo, L. 2011. Towards vehicular sensor networks with android smartphones for road surface monitoring, in The Second International Workshop on Networks of Cooperating Objects (CONET'11): Electronic Proceedings of CPSWeek'11, 11 April 2011, Chicago, US, 1-4.

TRRL. 1991. Towards Safer Roads in Developing Countries: a Guide for Planners and Engineers. Transport and Road Research Laboratory (TRRL), Crowthorne, UK. 220 p. 
TRB. 2004. Automated Pavement Distress Collection Techniques. National Cooperative Highway Research Program (NCHRP) Synthesis 334. Transportation Research Board (TRB), Washington, DC, US. https://doi.org/10.17226/23348

TRB. 2010. Highway Capacity Manual. 5th edition. Transportation Research Board (TRB), Washington, DC, US. 1650 p.

Van Arem, B.; Van Der Vlist, M.J.M.; De Ruiter, J. C. C.; Muste, M.; Smulders, S. A. 1994. Design of the Procedures for Current Capacity Estimation and Travel Time and Congestion Monitoring. General European Road Data Information Exchange Network (GERDIEN). DRIVE-II Project No V2044, Deliverable No 9, Technical Annex 2 (Revised), Workpackage No. SP6.WP2 \& SP6.WP3. 71 p. Available from Internet: http://publicaties.minienm.nl/documenten/design-of-theprocedures-for-current-capacity-estimation-and-tra

Walker, D.; Entine, L.; Kummer, S. 2002. Pavement surface evaluation and rating: asphalt Roads Paser Manual. Transportation Information Center, University of Wisconsin-Madison, US. $32 \mathrm{p}$.

Wang, K. C. P. 2000. Designs and implementations of automated systems for pavement surface distress survey, Journal of Infrastructure Systems 6(1): 24-32.

https://doi.org/10.1061/(ASCE)1076-0342(2000)6:1(24)

Žilioniené, D.; De Luca, M.; Dell'Acqua, G. 2013. Evaluation of climatic factors based on the mechanistic-empirical pavement design guide, The Baltic Journal of Road and Bridge Engineering 8(3): 158-165. https://doi.org/10.3846/bjrbe.2013.20 